\title{
INFESTAÇÃo DE GIRASSOL PELA LAGARTA Chlosyne lacinia saundersii EM DUAS ÉPOCAS DE CULTIVO
}

\author{
A.L. BOIÇA JUNIOR \\ Departamento de Entomologia e Nematologia - FCAV/UNESP - CEP: 14870-000-Jaboticabal,SP. \\ J.D. VENDRAMIN \\ Departamento de Entomologia - ESALQ/USP - CEP: 13418-900-Ptracicaba,SP.
}

\begin{abstract}
RESUMO: Verificou-se o comportamento de cultivares de girassol em relaçăo ao ataque de Chlosyne lacinia saundersi $i$ em condiçôes de campo, avaliando-se o aúmero de lagartas por planta, número de lagartas por metro linear de plantas, porcentagem de plantas atacadas e porcentagem de desfolha. Concluiu-se que: a) os métodos mais adequados para a avaliaçâo da infestaçāo desse inseto foram a porcentagem de plantas atacadas e o número de lagartas por metro linear de plantas; b) as cultivares de girassol menos infestadas pela praga foram 'Cargill-33', 'Contissol', 'Issanka-F', 'PIGB', 'Uruguai' e 'Contissol-621', enquanto 'Contissol-711', 'Contissol-112' e 'Rumano-P4' foram as mais infestadas e, c) a ocorrencia de $C$. lacinia saundersil foi maior na segunda epoca de cultivo (fevereiro a junho) do que na primeira (outubro a fevereiro).
\end{abstract}

Descritares: resistencia de plantas a insetos, Chlosyne lacinia saundersil, Helianthus annuus, girassol.

\section{SUNFLOWER INFESTATION BY Chlosyne lacinia saundersü IN TWO CROPPING SEASONS}

\begin{abstract}
The behavior of sunflower cultivars was evaluated in relation to the attack of Chlosyne lacinia saundersil, under field conditions. The following parameters were evaluated: number of larvae per plant, number of larvae per linear meter of plants, percentage of attacked plants and percentage of defoliation. The results were as follows: the most suitable methods for evaluating the insect infestation were the pencentage of attacked plants and the number of larvae per linear meter of plants; the less infested sunflower cultivars were 'Cargill-33', 'Contissol', 'Issanka-F', 'PIGB', 'Uruguai' and 'Contissol-621', while 'Contissol-711', 'Contissol-112', and 'Rumano-P4' were the most infested ones. The occurrence of $C$. lacinia saundersii was higher in the second period of cultivation (February to June) than in the first (October to February).

Key Wonds: crop resistance to insects, Chlosyne lacinla saundersii, Helianthus annuus, sunflower.
\end{abstract}

\section{INTRODUÇÃO}

0 centro de origem do girassol, Helianthus annuus L. (Asteraceae), é controvertido. Enquanto alguns pesquisadores indicam a América do Norte, outros se referem ao Peru e ao México. Seu plantio permaneceu, durante séculos, confinado às regiōes de origem $e$, somente a partir do século XVII, teve certa expansão para outras partes do mundo.

Neste particular, foi somente após o século XIX que a cultura passou a ser mais divulgada, principalmente pelas suas qualidades como planta oleaginosa (ROGERS \& THOMPSON, 1980).
A cultura defronta-se com alguns

problemas para o incremento da produtividade $\mathrm{e}$, dentre estes, destacam-se os insetos, como os coleópteros, percevejos e principalmente a lagarta-do-girassol, Chlosyne lacinia saundersii Doubleday \& Hewitson, 1849 (Lepidoptera, Nymphalidae).

NAKANO et al. (1981), estudando a biologia desse inseto em plantas de girassol, constataram para o período de incubação, fase larval, fase pupa e longevidade de adultos, valores de 8 a $9,23,6$ a 7 e 5 a 6 dias, respectivamente.

As lagartas do gênero Chlosyne alimentam-se comumente das lâminas foliares, deixando as nervuras com aspecto rendilhado (SCOTT, 1968; PARO JR. \& NAKANO, 1976; BOIÇA JUNIOR et al., 1984). 
PARO JR. \& NAKANO (1976) com o objetivo de demonstrar a nocividade de $C$. lacinia saundersii à cultura de girassol, desenvolveram um ensaio com simulação de danos foliares em diferentes estádios de desenvolvimento dessa cultura. Assim, com base em desfolhas artificiais, constataram que os danos provocados antes dos $\mathbf{4 0}$ dias de idade da planta levaram à redução total da produção, enquanto que, no periodo de 48 a 68 dias de idade, o desfolhamento causou uma redução na produção da ordem de 72 a $85 \%$. Foi constatada redução de matéria graxa apenas com danos provocados em plantas com 58 a 68 dias.

Em Londrina,PR, VILLAS BOAS \& MOSCARDI (1985), efetuando uma desfolha artificial em plantas de girassol, concluíram que nos estágios de $50 \%$ e $75 \%$ da floração, as plantas se mostraram mais suscetíveis, com redução no rendimento de grão oscilando entre 43,6 e $91,1 \%$. Com $25 \%$ de desfolha, não ocorreu redução significativa em qualquer estágio fenológico da planta. Desfolhas efetuadas ao final da fase de enchimento dos grãos também não provocaram redução na produção.

Com relação ao controle desse inseto, as referências se restringem praticamente aos métodos químicos, cujos efeitos prejudiciais ao ambiente são bastante conhecidos.

Deste modo, métodos alternativos, como a utilização de plantas resistentes, são de grande importância, principalmente por ser reconhecido como o método ideal de controle, pois mantém a população da praga abaixo dos níveis de dano econômico sem causar distúrbios ou poluiçãa ao ecossistema, e ainda, sem acarretar ônus adicional ao agricultor (LARA, 1991).

No entanto, esta área de pesquisa encontra-se bem mais avançada em outros países, principalmente nos EUA, onde as referências bibliograficas destacam trabalhos enfocando algumas pragas em girassol, importantes para aquela região mas de pouca ou nenhuma importância para o Brasil. Dentre estas, destacam-se a Zygogramma exclamationis (Fabricius) (Coleoptera, Chrysomelidae), Bothynus gibbosus (De Geer) (Coleoptera, Scarabaeidae), Masonaphis masoni (Knowlton) (Hemiptera, Aphididae), Empoasca sp. (Hemiptera, Cicadellidae), Homoeosoma electellum (Hulst) (Lepidoptera, Pyralidae) e outros insetos sugadores (ROGERS \& THOMPSON, 1980).

No Brasil, um dos únicos trabalhos relatados é o de LOURENÇÃO \& UNGARO
(1983), que, trabalhando em Campinas, SP, com 18 cultivares de girassol, verificaram, em dois experimentos conduzidos em condições de campo, que as cultivares Cargill-33 e Estanzuella-75, com valores de $20,0 \%$ e $19,0 \%$ de desfolha, em média, respectivamente, comportaram-se como as mais resistentes ao ataque de $C$. lacinia saundersii, enquanto 'Conti GH-8121' foi a que apresentou maior porcentagem de desfolha pelas lagartas dessa espécie, com índice médio de $57,8 \%$.

Assim, o objetivo do presente trabalho foi o de avaliar o comportamento de cultivares de girassol em relação ao ataque de $C$. lacinia saundersii, em condições de campo.

\section{MATERIAL E MÉTODOS}

O experimento foi desenvolvido na Fazenda Experimental da UNESP (Universidade Estadual Paulista), Campus de Ilha Solteira, SP, situada no município de Selvíria,MS, em um solo do tipo Latossol Vermelho escuro, textura argilosa, segundo classificação de DEMATTÊ (1980).

Foram utilizadas duas épocas de cultivo, a primeira correspondendo ao período de outubro a fevereiro (semeadura em 27/10/87) e a segunda correspondendo ao período de fevereiro a junho (semeadura em 23/02/88).

$O$ delineamento experimental utilizado foi blocos casualizados com 16 cultivares correspondentes aos tratamentos principais e 4 tratamentos secundários (Épocas), com 10 repetições, totalizando 170 parcelas em cada época. As cultivares estudadas foram: Issanka-F, Perucci, PIGB, Contissol-711, Contissol-112, IAC-Anhandy, Progress, Semente Branca-Ivaí, Contissol, Cargill-33, Uruguai, Contissol-422, Rumano-P4, 6B x Ilnissey, Contissol-621 e DK-180.

As parcelas constaram de uma linha de $3 \mathrm{~m}$ de comprimento, num espaçamento de $0,80 \mathrm{~m}$ entre linhas, perfazendo, portanto, uma área de $2,4 \mathrm{~m}^{2}$, numa densidade de 10 a 15 sementes por metro linear. Aos 30 dias após a emergência das plantas, efetuou-se o desbaste, deixando-se 5 a 6 plantas por metro linear, além de se realizar uma capina manual.

Como adubação de semeadura, utilizaram-se $300 \mathrm{~kg} / \mathrm{ha}$ da fórmula 4-30-10 e como adubação de cobertura empregaram-se $30 \mathrm{~kg}$ de nitrogênio/ha, na forma de sulfato de amônio, aos 30 dias após a emergência.

As avaliações foram realizadas em 4 épocas, aos 30, 45, 60 e 75 dias após a emergência 
das plantas, observando-se, em cada parcela, os seguintes parâmetros:

- Número de lagartas por planta (amostradas em 5 plantas ao acaso);

- Número de lagartas por metro linear de plantas;

- Porcentagem de plantas atacadas (amostrada em 5 plantas ao acaso);

- Porcentagem de desfolha (amostrada visualmente em 5 plantas ao acaso).

As médias dos parâmetros foram comparadas pelo teste de Tukey ao nível de $5 \%$ de probabilidade, efetuando-se para porcentagens de plantas atacadas e de desfolha a transformação arc sen $\sqrt{ } \mathrm{P} / 100$, e, para os demais parâmetros, $\checkmark x+0,5$. A comparação entre os métodos de amostragem, para as duas épocas de cultivo foi feita através do teste de homocedasticidade de Bartlett.

\section{RESULTADOS E DISCUSSÃO}

Pelos dados da TABELA 1, nota-se que não houve interação significativa para cultivares vs. épocas de cultivo, para número de lagartas por planta.

Analisando-se as médias obtidas nas duas épocas de cultivo, constatam-se diferenças estatísticas para a segunda, sendo que a média da cultivar Rumano-P4 foi significativamente superior aquelas observadas para 'Cargill-33' e 'Perucci', apresentando os demais materiais valores intermediários.

Pelos dados médios das duas épocas de cultivo constataram-se diferenças estatísticas entre as cultivares. A 'Rumano-P4' apresentou infestação significativamente superior à registrada em 'Cargill-33', sugerindo que esta apresenta certa resistência ao ataque de $C$. lacinia saundersii, concordando com relatos apresentados por LOURENÇÃO \& UNGARO (1983).

Com respeito à média de todas as cultivares, em cada época, observa-se que a maior incidência da praga ocorreu na segunda época de cultivo (fevereiro a junho), diferindo significativamente da primeira (outubro a fevereiro), concordando com as observações de BOIÇA JUNIOR et al. (1984), efetuadas na mesma localidade.
Observa-se também através da Figura 1, que na primeira época de cultivo, a maior infestação ocorreu aos 75 dias após a emergência das plantas, embora sem apresentar variação em relação ao ataque aos $\mathbf{4 5}$ dias, enquanto que na segunda época o pico de infestação se deu aos 45 dias.

Analisando-se os dados da TABELA 2, constata-se que, também para o número de lagartas por metro linear, não houve interação significativa para cultivares vs. épocas de cultivo.

Considerando-se a segunda época de cultivo, constataram-se diferenças estatísticas, sendo que a média referente à cultivar Rumano-P4 foi significativamente superior àquelas registradas em 'Perucci' e 'Cargill-33'.

Pelos dados médios das duas épocas de cultivo, não se verificam diferenças estatísticas entre as cultivares.

Quanto à média de todas as cultivares em cada época, observa-se que a maior incidência de C. lacinia saundersii foi na segunda época.

A observação dos dados da Figura 1 evidencia a semelhança entre os resultados obtidos através da avaliação do número de lagartas por planta e número de lagartas por metro linear de plantas, embora obviamente os valores numéricos tenham sido maiores no segundo caso.

Observando-se os dados da porcentagem de plantas atacadas (TABELA 3), constata-se diferença estatística significativa para a interação cultivares vs. épocas de cultivo, onde, pelo desdobramento da mesma, verifica-se efeito de cultivares em ambas as épocas de cultivo. $\mathrm{Na}$ primeira, observa-se que a porcentagem de plantas atacadas na cultivar Contissol-112 foi significativamente maior que a obtida $\mathrm{cm}$ 'Issanka-F' e 'PIGB'.

Para a segunda época, a porcentagem média da cultivar Perucci foi estatisticamente inferior à observada em 'Contissol-422', apresentando-se as demais com valores intermediários.

Em relação ao efeito de épocas de cultivo dentro de cultivar, nota-se que, para todas as cultivares, a incidência da praga na segunda época de cultivo foi significativamente superior a registrada na primeira época (TABELA 3).

Observando-se, por outro lado, o conjunto das porcentagens médias das duas épocas de cultivo, para cada cultivar, nota-se que não houve diferenças estatísticas entre as 16 cultivares testadas. 
TABELA 1 - Número médio de lagartas de Chlosyne lacinia saundersii por planta em 16 cultivares de girassol, em duas épocas de cultivo. Selvíria,MS, 1987 e 1988.

\begin{tabular}{|c|c|c|c|c|}
\hline \multirow[b]{2}{*}{ Cultivares } & \multicolumn{2}{|c|}{ Epocas de Cultivo } & \multirow[b]{2}{*}{ Média ${ }^{1}$} & \multirow[b]{2}{*}{ Teste $\mathbf{F}$} \\
\hline & Out/Fev & Fev/Jun & & \\
\hline Rumano $\mathbf{P}_{4}$ & $2,04 \mathrm{a}$ & $13,90 \mathrm{a}$ & $7,97 \mathrm{a}$ & - \\
\hline Contissol - 422 & $6,72 a$ & $8,59 a b$ & $7,66 \mathrm{ab}$ & - \\
\hline 6 B x Ilnissey & $4,06 a$ & $9,54 a b$ & $6,80 \mathrm{ab}$ & - \\
\hline Contissol - 711 & $3,92 a$ & $9,22 \mathrm{ab}$ & $6,57 a b$ & - \\
\hline D K - 180 & $5,84 a$ & $6,80 \mathrm{ab}$ & $6,32 a b$ & - \\
\hline Contissol - 112 & $3,89 a$ & $8,19 a b$ & $6,04 a b$ & - \\
\hline IAC - Anhandy & $4,01 a$ & $7,25 a b$ & $5,63 \mathrm{ab}$ & - \\
\hline Uruguai & $4,78 \mathrm{a}$ & $5,84 a b$ & $5,31 a b$ & - \\
\hline Contissol - 621 & $2,88 \mathrm{a}$ & $7,56 \mathrm{ab}$ & $5,22 \mathrm{ab}$ & - \\
\hline Semente Branca - Ivaí & $2,51 \mathrm{a}$ & $6,81 \mathrm{ab}$ & $4,66 \mathrm{ab}$ & - \\
\hline Progress & $2,83 a$ & $6,28 a b$ & $4,56 a b$ & - \\
\hline PIGB & $1,12 \mathrm{a}$ & $7,42 \mathrm{ab}$ & $4,27 \mathrm{ab}$ & - \\
\hline Contissol & $1,58 \mathrm{a}$ & $6,52 \mathrm{ab}$ & $4,05 \mathrm{ab}$ & - \\
\hline Issanka - F & $1,28 \mathrm{a}$ & $6,76 a b$ & $4,02 \mathrm{ab}$ & - \\
\hline Perucci & $1,65 \mathrm{a}$ & $3,28 \mathrm{~b}$ & $2,46 a b$ & - \\
\hline Cargill - 33 & $1,56 \mathrm{a}$ & $2,65 b$ & $2,10 \mathrm{~b}$ & - \\
\hline Média $^{1}$ & 3,17 B & $7,29 \mathrm{~A}$ & - & $89,55^{-\infty}$ \\
\hline Teste F & $1,38^{\mathrm{NS}}$ & $2,93^{* *}$ & $2,37^{-}$ & $1,65^{\mathrm{NS2}}$ \\
\hline
\end{tabular}

${ }^{1}$ Médias seguidas de letras diferentes (maiúsculas nas linhas e minúsculas nas colunas) diferem estatisticamente pelo teste de Tukey, ao nível de $5 \%$ de probabilidade.

${ }^{2}$ Interação (cultivares vs. épocas de avaliação).

Em relação à média geral das cultivares, para cada Época de cultivo, observa-se incidência significativamente maior da praga na segunda época de cultivo. De modo geral, para a porcentagem de plantas atacadas (Figura 2), os valores cresceram até atingir um pico aos 60 dias de idade das plantas, tanto no primeiro como no segundo plantio de girassol, decrescendo na última época de avaliação.

Sci. agric., Piracicaba, 50(2):244-253, jun/set., 1993
Pelos dados da porcentagem de desfolha (TABELA 4), observa-se diferença significativa para a interação cultivares vs. épocas de cultivo. Em relação ao efeito de cultivares, verificam-se diferenças estatísticas entre as 16 cultivares para ambas as épocas de cultivo. Para a primeira, a cultivar 6B $x$ Ilnissey, teve uma porcentagem significativamente superior àquela registrada em 'PIGB'. 
TABELA 2 - Número médio de lagartas de Chlosyne lacinia saundersii por metro linear de plantas em 16 cultivares de girassol, em duas Epocas de cultivo. Selvíria,MS, 1987 e 1988.

\begin{tabular}{|c|c|c|c|c|}
\hline \multirow[b]{2}{*}{ Cultivares } & \multicolumn{2}{|c|}{ Epocas de Cultivo } & \multirow[b]{2}{*}{ Média 1} & \multirow[b]{2}{*}{ Teste F } \\
\hline & Out/Eev & Fev/lun & & \\
\hline Contissol - 422 & $27,37 a$ & $31,70 \mathrm{ab}$ & $29,53 a$ & - \\
\hline D K -180 & $25,83 a$ & $31,62 \mathrm{ab}$ & $28,72 a$ & - \\
\hline Contissol - 711 & $21,36 \mathrm{a}$ & $34,28 \mathrm{ab}$ & $27,82 \mathrm{a}$ & - \\
\hline Rumano - $P_{4}$ & $4,82 a$ & $46,26 \mathrm{a}$ & $25,54 a$ & - \\
\hline Contissol - 112 & $14,06 \mathrm{a}$ & $33,04 a b$ & $23,55 \mathrm{a}$ & - \\
\hline 6 B x Ilnissey & $11,84 \mathrm{a}$ & $33,89 \mathrm{ab}$ & $22,86 a$ & - \\
\hline Contissol - 621 & $14,42 \mathrm{a}$ & $30,80 \mathrm{ab}$ & $22,61 \mathrm{a}$ & - \\
\hline Semente Branca - Ivaí & $10,84 a$ & $30,82 \mathrm{ab}$ & $20,83 a$ & - \\
\hline IAC - Anhandy & $14,38 \mathrm{a}$ & $22,64 \mathrm{ab}$ & $18,51 \mathrm{a}$ & - \\
\hline PIGB & $6,87 \mathrm{a}$ & $28,28 \mathrm{ab}$ & $17,57 \mathrm{a}$ & - \\
\hline Contissol & $9,59 a$ & $25,18 \mathrm{ab}$ & $17,38 \mathrm{a}$ & - \\
\hline Progress & $8,05 a$ & $25,84 \mathrm{ab}$ & $16,94 a$ & - \\
\hline Uruguai & $14,27 \mathrm{a}$ & $19,39 \mathrm{ab}$ & $16,83 a$ & - \\
\hline Perucci & $14,94 \mathrm{a}$ & $13,26 b$ & $14,10 \mathrm{a}$ & - \\
\hline Issanka - F & $3,04 a$ & $24,59 \mathrm{ab}$ & $13,81 a$ & - \\
\hline Cargill _ 33 & $9.06 a$ & $13.52 \mathrm{~b}$ & $11,29 a$ & $=$ \\
\hline MÉdia ${ }^{1}$ & $13.17 \mathrm{~B}$ & $27.82 \mathrm{~A}$ & - & $78.58=$ \\
\hline Teste F & $1.22^{\mathrm{NS}}$ & $2.27^{-*}$ & $1.81^{\mathrm{ns}}$ & $1.68^{\mathrm{NS2}}$ \\
\hline
\end{tabular}

${ }^{1}$ Médias seguidas de letras diferentes (maiúsculas nas linhas e minúsculas nas colunas) diferem estatisticamente pelo teste de Tukey, ao nível de $5 \%$ de probabilidade.

${ }^{2}$ Interação (cultivares vs. Épocas de avaliação).

\section{Numero de lagartas}

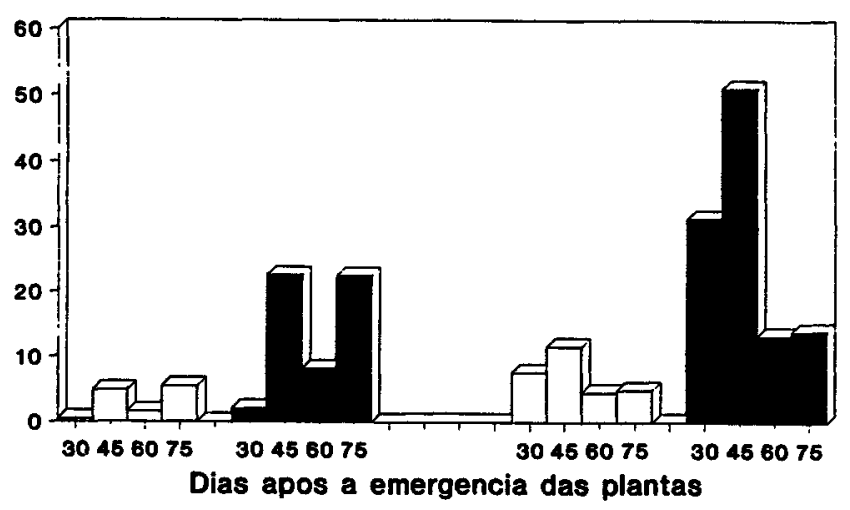

$\square$ Por planta $\square$ Por metro linear

Figura 1 - Número de lagartas de Chlosyne lacinia saundersii por planta e por metro linear de plantas, nas $1^{2}$ e $2^{a}$ épocas de cultivo, em quatro épocas de avaliação. Selvíria,MS, 1987 e 1988.

Sci. agric., Piracicaba, 50(2):244-253, jun/set., 1993 
TABELA 3 - Porcentagens média de plantas atacadas por lagartas de Chlosyne lacinia saundersii em 16 cultivares de girassol, em duas épocas de cultivo. Selvíria,MS, 1987 e 1988.

\begin{tabular}{|c|c|c|c|c|}
\hline \multirow[b]{2}{*}{ Cultivares } & \multicolumn{2}{|c|}{ Épocas de Cultivo } & \multirow[b]{2}{*}{ Média ${ }^{1}$} & \multirow[b]{2}{*}{ Teste F } \\
\hline & Out/Fey & Fev/lun & & \\
\hline Contissol - 112 & $21,55 \mathrm{Ba}$ & $63,49 \mathrm{Aab}$ & $42,52 a$ & $25,16^{* *}$ \\
\hline Contissol - 711 & $18,97 \mathrm{Bab}$ & $60,61 \mathrm{Aab}$ & $39,79 a$ & $27,39^{*+}$ \\
\hline Contissol - 422 & $11,82 \mathrm{Bab}$ & $65,14 \mathrm{Aa}$ & $38,48 a$ & $50,79^{* *}$ \\
\hline Contissol - 621 & $8,14 \mathrm{Bab}$ & $64,27 \mathrm{Aab}$ & $36,20 \mathrm{a}$ & $64,74^{* *}$ \\
\hline Rumano $-\mathrm{P}_{4}$ & $6,26 \mathrm{Bab}$ & $63,23 \mathrm{Aab}$ & $34,74 a$ & $67,77^{* *}$ \\
\hline IAC - Anhandy & $19,57 \mathrm{Bab}$ & $49,81 \mathrm{Aab}$ & $34,69 \mathrm{a}$ & $20,63^{* *}$ \\
\hline 6 B x Ilnissey & $12,37 \mathrm{Bab}$ & $56,20 \mathrm{Aab}$ & $34,28 \mathrm{a}$ & $39,88^{* *}$ \\
\hline D K -180 & $15,81 \mathrm{Bab}$ & $49,44 \mathrm{Aab}$ & $32,62 a$ & $21,09^{-*}$ \\
\hline Uruguai & $16,28 \mathrm{Bab}$ & $47,28 \mathrm{Aab}$ & $31,78 \mathrm{a}$ & $18,21^{\cdots+}$ \\
\hline Contissol & $6,27 \mathrm{Bab}$ & $57,09 \mathrm{Aab}$ & $31,68 \mathrm{a}$ & $55,47^{*-}$ \\
\hline Sementes Branca - Ivaí & $11,96 \mathrm{Bab}$ & $49,20 \mathrm{Aab}$ & $30,58 a$ & $31,77^{* *}$ \\
\hline Perucci & $17,99 \mathrm{Bab}$ & $42,99 \mathrm{Ab}$ & $30,49 a$ & $11,70^{* *}$ \\
\hline PIGB & $4,79 \mathrm{Bb}$ & $55,65 \mathrm{Aab}$ & $30,22 a$ & $63,01^{\cdots}$ \\
\hline Progress & $9,15 \mathrm{Bab}$ & $51,07 \mathrm{Aab}$ & $30,11 \mathrm{a}$ & $40,31^{-*}$ \\
\hline Issanka - F & $4,62 \mathrm{Bb}$ & $50,59 \mathrm{Aab}$ & $27,61 a$ & $51,24^{-*}$ \\
\hline Cargill -33 & $10.60 \mathrm{Bab}$ & $43,90 \mathrm{Aab}$ & $27,25 \mathrm{a}$ & $31,60^{*-}$ \\
\hline Média' & $12.26 \mathrm{~B}$ & $54,37 \mathrm{~A}$ & & $587,36^{* *}$ \\
\hline Teste F & $2.85^{-*}$ & $196^{*}$ & $1.70^{\mathrm{NS}}$ & $2.23^{*-2}$ \\
\hline
\end{tabular}

'Médias seguidas de letras diferentes (maiúsculas nas linhas e minúsculas nas colunas) diferem estatisticamente pelo teste de Tukey, ao nível de $5 \%$ de probabilidade.

${ }^{2}$ Interação (cultivares vs. épocas de avaliação).

\section{Porcentagem (\%)}

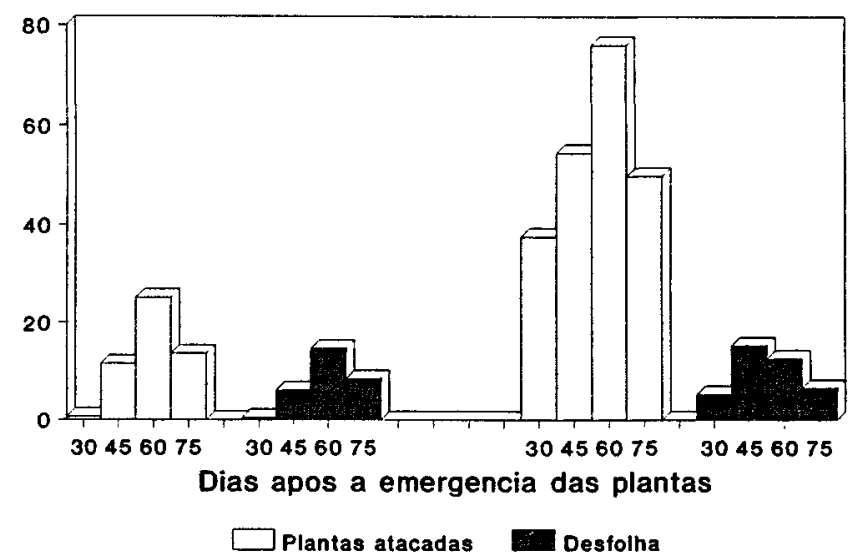

Figura 2 - Porcentagem de plantas atacadas e de desfolha de Chlosyne lacinia saundersii nas $1^{\mathrm{a}}$ e $2^{\mathrm{a}}$ épocas de cultivo, em quatro épocas de avaliação. Selvíria,MS, 1987 e 1988. 
TABELA 4 - Porcentagem média de desfolha causada por lagartas de Chlosyne lacinia saundersii em 16 cultivares de girassol, em duas épocas de cultivo. Selvíria,MS, 1987 e 1988.

\begin{tabular}{lccccc}
\hline \hline & \multicolumn{2}{c}{ Épocas de Cultivo } & & \\
\cline { 2 - 4 } \multicolumn{1}{c}{ Cultivares } & Out/Fev & Fev/Jun & Média & Teste F \\
\hline 6 B x Ilnissey & $14,62 \mathrm{a}$ & $8,07 \mathrm{ab}$ & $11,34 \mathrm{a}$ & $0,26^{\mathrm{NS}}$ \\
Contissol - 112 & $11,53 \mathrm{ab}$ & $10,22 \mathrm{ab}$ & $10,87 \mathrm{a}$ & $0,14^{\mathrm{NS}}$ \\
Contissol - 621 & $9,64 \mathrm{ab}$ & $11,67 \mathrm{ab}$ & $10,66 \mathrm{a}$ & $3,10^{\mathrm{NS}}$ \\
Contissol - 711 & $8,82 \mathrm{ab}$ & $10,90 \mathrm{ab}$ & $9,86 \mathrm{a}$ & $1,38^{\mathrm{NS}}$ \\
IAC - Anhandy & $9,94 \mathrm{ab}$ & $9,55 \mathrm{ab}$ & $9,74 \mathrm{a}$ & $0,42^{\mathrm{NS}}$ \\
D K - 180 & $8,56 \mathrm{ab}$ & $9,85 \mathrm{ab}$ & $9,20 \mathrm{a}$ & $0,67^{\mathrm{NS}}$ \\
Progress & $6,97 \mathrm{ab}$ & $10,65 \mathrm{ab}$ & $8,81 \mathrm{a}$ & $2,39^{\mathrm{NS}}$ \\
PIGB & $2,23 \mathrm{Bb}$ & $15,30 \mathrm{Aa}$ & $8,76 \mathrm{a}$ & $17,16^{-}$ \\
Rumano - P & $2,87 \mathrm{Bab}$ & $14,15 \mathrm{Aa}$ & $8,51 \mathrm{a}$ & $14,81^{-}$ \\
Contissol - 422 & $3,96 \mathrm{Bab}$ & $12,77 \mathrm{Aa}$ & $8,36 \mathrm{a}$ & $9,62^{-*}$ \\
Uruguai & $8,02 \mathrm{ab}$ & $8,67 \mathrm{ab}$ & $8,34 \mathrm{a}$ & $0,09^{\mathrm{NS}}$ \\
Semente Branca - Ivai & $8,12 \mathrm{ab}$ & $8,40 \mathrm{ab}$ & $8,26 \mathrm{a}$ & $0,42^{\mathrm{NS}}$ \\
Issanka - F & $3,54 \mathrm{Bab}$ & $12,39 \mathrm{Aa}$ & $7,96 \mathrm{a}$ & $10,11^{--}$ \\
Cargill - 33 & $7,07 \mathrm{ab}$ & $6,87 \mathrm{ab}$ & $6,97 \mathrm{a}$ & $1,13^{\mathrm{NS}}$ \\
Perucci & $6,65 \mathrm{ab}$ & $7,12 \mathrm{ab}$ & $6,88 \mathrm{a}$ & $0,26^{\mathrm{NS}}$ \\
Contissol & $4,97 \mathrm{ab}$ & $3,92 \mathrm{~b}$ & $4,44 \mathrm{a}$ & $0,29^{\mathrm{NS}}$ \\
\hline Média & $7,34 \mathrm{~B}$ & $10,03 \mathrm{~A}$ & - & $33,48^{* *}$ \\
\hline Teste F & $1,91^{*}$ & $2,84^{-}$ & $1,16^{\mathrm{NS}}$ & $1,92^{-2}$ \\
\hline \hline
\end{tabular}

1 Médias seguidas de letras diferentes (maiúsculas nas linhas e minúsculas nas colunas) diferem estatisticamente pelo teste de Tukey, ao nível de $5 \%$ de probabilidade.

${ }^{2}$ Interação (cultivares vs. épocas de avaliação).

Para a segunda época de cultivo, notam-se porcentagens de desfolha maiores para as cultivares PIGB, Rumano-P4, Contissol-422 e Issanka-F, as quais diferiram estatisticamente da 'Contissol'.

Para o efeito de épocas de cultivo dentro de cultivar, notam-se diferenças significativas para as cultivares PIGB, Rumano - P4, Contissol-422 e Issanka-F, sendo que, a maior incidência do inseto foi observada na segunda época de cultivo.
Pela análise da média geral da porcentagem de desfolha das duas épocas de cultivo, para cada cultivar, constata-se que não houve diferenças estatísticas entre as 16 cultivares testadas.

Quanto a média geral das cultivares para cada época, observa-se maior ataque da praga na segunda época de cultivo, diferindo significativamente daquela observada na primeira época (TABELA 4). 
TABELA 5 - Comparação entre a variabilidade em cada método de avaliação da infestação de Chlosyne lacinia saundersii, em relação aos cultivares testados, pelo teste de Bartlett, na primeira epoca de cultivo de girassol. Selvíria,MS, outubro de 1987 a fevereiro de 1988.

\begin{tabular}{lcccc}
\hline & \multicolumn{3}{c}{ Métodos $^{2}$} \\
\cline { 2 - 5 } Cultivares & N L P & N L M & P P A & P D L \\
\hline Contissol - 422 & 1424,59 & 650,44 & 148,74 & 36,80 \\
Contissol - 621 & 929,75 & 929,75 & 176,15 & 276,13 \\
IAC - Anhandy & 875,59 & 674,43 & 395,62 & 198,48 \\
Rumano P & 826,45 & 102,19 & 102,50 & 40,57 \\
Uruguai & 825,96 & 473,78 & 178,10 & 39,87 \\
Contissol - 711 & 632,18 & 729,46 & 264,19 & 134,66 \\
D K - 180 & 613,38 & 469,91 & 241,91 & 110,45 \\
6 B x Ilnissey & 590,38 & 319,01 & 234,72 & 243,32 \\
Progress & 369,89 & 198,91 & 112,66 & 87,78 \\
Contissol - 112 & 356,82 & 304,52 & 241,75 & 197,95 \\
Semente Branca - Ivaí & 350,65 & 275,90 & 197,83 & 60,09 \\
PIGB & 313,60 & 471,97 & 79,20 & 20,55 \\
Contissol & 267,00 & 270,63 & 84,81 & 84,76 \\
Issanka - F & 182,27 & 81,57 & 44,04 & 40,89 \\
Perucci & 166,58 & 220,32 & 157,72 & 65,29 \\
Cargill - 33 & 128,18 & 173,03 & 422,67 & 287,79 \\
\hline E (Bartlett) & $28,93^{*}$ & $28,26^{*}$ & $21,48^{\text {Ns }}$ & $42,04^{* *}$ \\
\hline \hline
\end{tabular}

${ }^{1}$ NLP = Número de lagartas por plantas; NLM = número de lagartas por metro linear de plantas;

$\mathrm{PPA}=$ porcentagem de plantas atacadas $\mathrm{PDL}=$ porcentagem de desfolha.

${ }^{2}$ Estatística do teste de homocedasticidade de Bartlett.

De modo geral, a porcentagem de desfolha foi maior quando as plantas apresentavam 60 dias na primeira época de cultivo, enquanto que na segunda, isto ocorreu aos 45 e 60 dias (Figura 2).

Comparando-seas duas épocas de cultivo, constata-se, ao observar os dados das Figuras 1 e 2 , que a população e consequentementeos danos da praga, foram maiores na segunda época de cultivo, na localidade em que se realizou o experimento, 0 que vem novamente ratificar os dados relatados por BOIÇA JÚNIOR et al. (1984).

Ao se analisar os dados das TABELAS 5 e 6, nota-se, pelo teste de Bartlett, que os parâmetros com menor variância (menor valor de E), foram a porcentagem de plantas atacadas, no primeiro cultivo, e este é o número de lagartas por metro linear de plantas no segundo cultivo, o que sugere, portanto, serem estes parâmetros os mais 
TABELA 6 - Comparação entre a variabilidade em cada método de avaliação da infestação de Chlosyne lacinia saundersii, em relação aos cultivares testados, pelo teste de Bartlett, na segunda época de cultivo de girassol. Selvíria,MS, fevereiro a junho de 1988.

\begin{tabular}{lcccc}
\hline & \multicolumn{4}{c}{ Métodos $^{1}$} \\
\cline { 2 - 5 } Cultivares & N L P & N L M & P P A & P D L \\
\hline Rumano P & 2449,57 & 1104,42 & 250,22 & 57,28 \\
Issanka - F & 1467,16 & 453,38 & 359,98 & 57,02 \\
Contissol - 711 & 1439,36 & 771,38 & 486,55 & 31,49 \\
Contissol - 422 & 1207,06 & 241,92 & 154,25 & 25,71 \\
PIGB & 1136,79 & 731,23 & 293,37 & 117,45 \\
Contissol - 621 & 1025,74 & 465,80 & 260,37 & 57,58 \\
Semente Branca - Ivai & 619,32 & 366,26 & 213,60 & 5,88 \\
Contissol - 112 & 610,32 & 323,09 & 268,01 & 13,93 \\
D K - 180 & 544,92 & 613,84 & 254,21 & 17,83 \\
6 B x Ilnissey & 347,17 & 166,86 & 131,86 & 6,37 \\
Perucci & 345,44 & 268,83 & 571,11 & 38,64 \\
Contissol & 327,21 & 224,86 & 796,14 & 6,48 \\
Uruguai & 284,32 & 214,98 & 457,81 & 36,30 \\
Cargill - 33 & 259,77 & 366,62 & 377,33 & 21,18 \\
Progress & 194,56 & 190,81 & 105,19 & 46,06 \\
IAC - Anhandy & 114,38 & 150,46 & 164,16 & 57,08 \\
\hline E (Bartlett) & $44,43^{*}$ & $23,56^{\text {ns }}$ & $19,67^{\text {Ns }}$ & $44,18^{* *}$ \\
\hline \hline
\end{tabular}

${ }^{1} \mathrm{NLP}=$ Número de lagartas por plantas; $\mathrm{NLM}=$ número de lagartas por metro linear de plantas;

PPA $=$ porcentagem de plantas atacadas; $\mathrm{PDL}=$ porcentagem de desfolha.

${ }^{2}$ Estatística do teste de hemocedasticidade de Bartlett.

confiáveis na determinação da diferença do ataque de C. Lacinia saundersii em girassol. Já no que se refere às diferenças de infestação sofrida pelas cultivares, em cada época de cultivo (TABELAS 1 a 4), pode-se relacionar, de modo geral, as cultivares Contissol-711, Contissol-112 e Rumano-P4, como as mais atacadas pela praga, e como menos atacadas, destacaram-se 'Cargill-33', 'Contissol', 'Issanka-F', 'PIGB', Uruguai' e 'Contissol-621'.

\section{CONCLUSÕES}

- Os métodos mais adequados para a avaliação da infestação de cultivares de girassol para $C$. lacinia saundersii são a porcentagem de plantas atacadas e o número de lagartas por metro linear de plantas;

- Em condições de campo, as cultivares de girassol menos infestadas pela praga são 'Cargill-33', 
'Contissol', 'Issanka-F', 'PIGB', 'Uruguai' e 'Contissol-621', enquanto 'Contissol-711', 'Contissol-112' e 'Rumano-P4', são as mais infestadas;

- A ocorrência de C. lacinia saundersii É maior na segunda época de cultivo (fevereiro a junho) do que na primeira (outubro a fevereiro).

\section{REFERÊNCIAS BIBLIOGRAFICAS}

BOIÇA JUNIOR, A.L.; BOLONHEZI, A.C.; PACCINI NETO, J. Levantamento de insetos-pragas e seus inimigos naturais em girassol (Helianthus annuus $\mathbf{L}$.), cultivada em primeira e segunda época, no município de Selvíria-MS. Anais da Sociedade Entomológica do Brasil, Jaboticabal, v.13, n.2, p.189-196, 1984

DEMATTÊ, J.L.I. Levantamento detalhado dos solos do 'campus' experimental da UNESP-Ilha Solteira. 1980. 131 p. (mimeografado).

LARA, F.M. Princípios de resistência de plantas a insetos. São Paulo, Cone, 1991. 336p.

LOURENÇÃO, A.L.; UNGARO, M.R. Preferência para alimentação de lagartas de Chlosyne lacinia saundersii Doubleday \& Hewitson, 1849 em cultivares de girassol. Bragantia, Campinas, v.42, p.281-286, 1983.
NAKANO, O.; SILVEIRA NETO, S.; ZUCCHI, R.A. Entomologia econômica. São Paulo, Livroceres, 1981. 314p.

PARO JR., L.A.; NAKANO, O. Dano simulado para a lagarta do girassol Chlosyne lacinia saundersii (Lepidoptera, Nymphalidae). Anais da Sociedade Entomologica do Brasil, Jaboticabal, v.5, n.2, p.216-234, 1976.

ROGERS, C.E.; THOMPSON, T.E. Helianthus resistance to the sunflower beetle (Coleoptera:Chrysomelidae). Journal of the Kansas Entomological Society, Manhattan, v.53, n.4, p.727-730, 1980.

SCOTT, J.A. The life history and habits of Chlosyne fulvia (Nymphalidae). Journal of the Lepidopterists' Society, New Haven, v.22, n.4, p.237-240, 1968.

VILLAS BÔAS, G.L.; MOSCARDI, F. Levantamento dos insetos-pragas do girassol e seus inimigos naturais. EMBRAPA. Resultados de Pesquisa de Girassol. Londrina: Centro Nacional de Pesquisa de Soja, 1985. p. 9-12.

Trabalho enviado para publicação em 03.11 .92 Trabalho aceito para publicação em 22.03 .93 